\title{
Mapping the climate change challenge
}

\author{
Stephane Hallegatte ${ }^{1 \star}$, Joeri Rogelj ${ }^{2,3}$, Myles Allen $^{4,5}$, Leon Clarke ${ }^{6}$, Ottmar Edenhofer ${ }^{7,8,9}$, \\ Christopher B. Field ${ }^{10,11}$, Pierre Friedlingstein ${ }^{12}$, Line van Kesteren ${ }^{13}$, Reto Knutti ${ }^{3}$, Katharine J. Mach ${ }^{11}$, \\ Michael Mastrandrea ${ }^{11}$, Adrien Michel ${ }^{14,15}$, Jan Minx ${ }^{7,9,16}$, Michael Oppenheimer ${ }^{17}$, Gian-Kasper \\ Plattner ${ }^{14,22}$, Keywan Riahi ${ }^{2,18}$, Michiel Schaeffer ${ }^{19,20}$, Thomas F. Stocker ${ }^{14,15}$ and Detlef P. van Vuuren ${ }^{13,21}$
}

\begin{abstract}
Discussions on a long-term global goal to limit climate change, in the form of an upper limit to warming, were only partially resolved at the United Nations Framework Convention on Climate Change negotiations in Paris, 2015. Such a political agreement must be informed by scientific knowledge. One way to communicate the costs and benefits of policies is through a mapping that systematically explores the consequences of different choices. Such a multi-disciplinary effort based on the analysis of a set of scenarios helped structure the IPCC AR5 Synthesis Report. This Perspective summarizes this approach, reviews its strengths and limitations, and discusses how decision-makers can use its results in practice. It also identifies research needs that can facilitate integrated analysis of climate change and help better inform policy-makers and the public.
\end{abstract}

A key component of international negotiations on climate change has been the agreement on a long-term global goal, in the form of an upper limit to warming, to "prevent dangerous anthropogenic interference with the climate system" (Article 2 of the United Nations Framework Convention on Climate Change, UNFCCC). The Paris Agreement now quantifies (for the first time) this goal as the objective to hold "the increase in the global average temperature to well below $2{ }^{\circ} \mathrm{C}$ above pre-industrial levels and to pursue efforts to limit the temperature increase to $1.5^{\circ} \mathrm{C}$ above preindustrial levels, recognizing that this would significantly reduce the risks and impacts of climate change".

The choice of this objective is the result of a long and complex political process that has been informed by the science of climate change, notably as summarized by the Fifth Assessment Report (AR5) Synthesis Report ${ }^{1}$ of the Intergovernmental Panel on Climate Change (IPCC), published in November 2014. Similarly, future decisions on efforts to hold the temperature increase below $1.5^{\circ} \mathrm{C}$ will be informed by existing and future IPCC assessments. The mandate of the organization is to inform decision-making at all levels (including international negotiations), and they responded positively to the invitation by the UNFCCC to "provide a special report in 2018 on the impacts of global warming of $1.5^{\circ} \mathrm{C}$ above pre-industrial levels and related global greenhouse gas emission pathways".

As the IPCC engages with the scientific community in scoping its report, it is essential to reaffirm that scientific analysis cannot, by itself, identify a single best long-term goal. One major reason is that individuals and groups have distinct values and priorities. Because climate and climate policy have a wide range of impacts that differ across countries, communities and individuals, a temperature target also depends on preferences regarding equity and fairness. The need to aggregate the wide variety of impacts also involves value judgments, for example, the relative importance ascribed to economic damages versus impacts that are harder to monetize, such as biodiversity loss. Another example is that the long-term goal depends on relative valuation of present versus future outcomes. As long as values and preferences vary widely, purely scientific methods cannot specify a unique and consensual upper limit for warming. A long-term goal for climate policy can be agreed upon only through a political process, both national and international ${ }^{2}$.

Science can inform such a process, through a mapping that systematically explores the consequences of different policy choices for climate change and the risks it creates ${ }^{3}$. Such a multi-disciplinary effort, based on the analysis of a set of scenarios, helped structure the IPCC AR5 Synthesis Report ${ }^{1}$. Here, we summarize this approach and - going beyond AR5 - review its strengths and limitations and discuss how decision-makers can use these results in practice, notably to think about future choices regarding the long-term objective of climate action. We also identify research needs to facilitate integrated analysis of the climate change problem and to help better inform policymakers and the public.

\footnotetext{
'The World Bank, Climate Change Policy Team, 1818 H Street NW, Washington, DC 20433, USA. Energy Program, International Institute for Applied Systems Analysis (IIASA), Schlossplatz 1, A-2361 Laxenburg, Austria. ${ }^{3}$ Institute for Atmospheric and Climate Science, ETH Zurich, Universitätstrasse 16, 8092 Zürich, Switzerland. ${ }^{4}$ Department of Physics, University of Oxford, Oxford OX1 3PU, UK. ${ }^{5}$ Environmental Change Institute, University of Oxford, Oxford OX1 3QY, UK. ${ }^{6}$ Pacific Northwest National Laboratories, Joint Global Change Research Institute, College Park, Maryland 20740, USA. ${ }^{7}$ Potsdam Institute for Climate Impact Research, Telegrafenberg, 14473 Potsdam, Germany. ${ }^{8}$ Technische Universität Berlin, 10623 Berlin, Germany. ${ }^{9}$ Mercator Research Institute on Global Commons and Climate Change, Torgauer Str. 12, 10829 Berlin, Germany. ${ }^{10}$ Department of Earth System Science, Stanford University, Stanford, California 94305, USA. "'Department of Global Ecology, Carnegie Institution for Science, 260 Panama Street, Stanford, California 94305, USA. ${ }^{12}$ College of Engineering Mathematics and Physical Sciences, University of Exeter, Exeter EX4 4QF, UK. ${ }^{13} \mathrm{PBL}$ Netherlands Environmental Assessment Agency, PO Box 303, 3720 AH Bilthoven, The Netherlands. ${ }^{14}$ Climate and Environmental Physics, Physics Institute, University of Bern, Sidlerstrasse 5, 3012 Bern, Switzerland. ${ }^{15}$ Oeschger Center for Climate Change Research, University of Bern, Falkenplatz 16, 3012 Bern, Switzerland. ${ }^{16} \mathrm{Hertie}$ School of Governance, Friedrichstrasse 189, 10117 Berlin, Germany. ${ }^{17}$ Department of Geosciences and the Woodrow Wilson School, Princeton University, Princeton, New Jersey 08544, USA. ${ }^{18} \mathrm{Graz}$ University of Technology, Inffeldgasse, A-8010 Graz, Austria. ${ }^{19} \mathrm{Climate}$ Analytics GmbH, Friedrichstrasse 231 , Haus B, 10969 Berlin, Germany. ${ }^{20}$ Environmental Systems Analysis Group, Wageningen University and Research Centre, PO Box 47, 6700 AA Wageningen, The Netherlands. ${ }^{21}$ Utrecht University, Copernicus Institute for Sustainable Development, Utrecht, The Netherlands. ${ }^{22}$ Swiss Federal Research Institute WSL, CH-8903 Birmensdorf, Switzerland. *e-mail: shallegatte@worldbank.org
} 
a

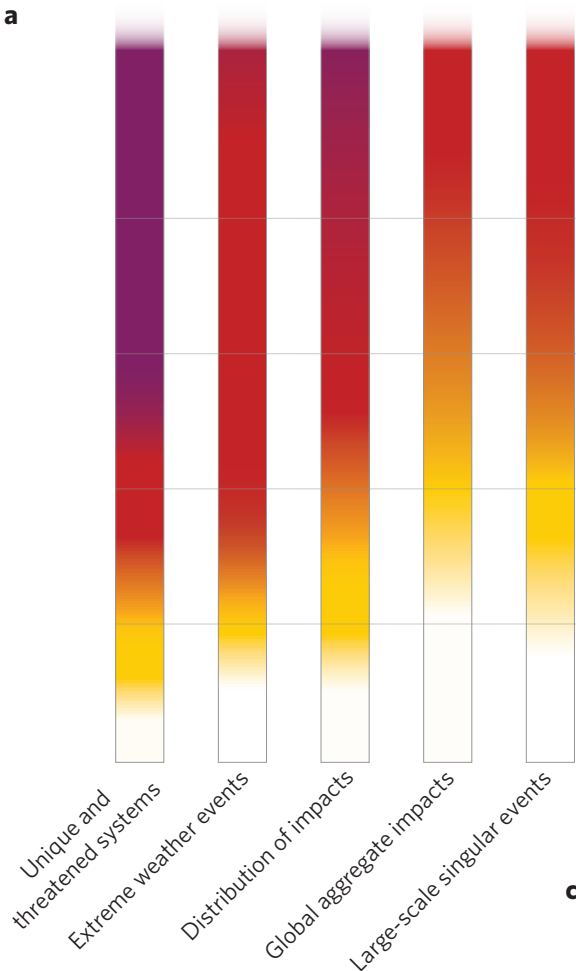

Level of additional risk due to climate change

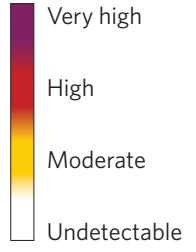

b

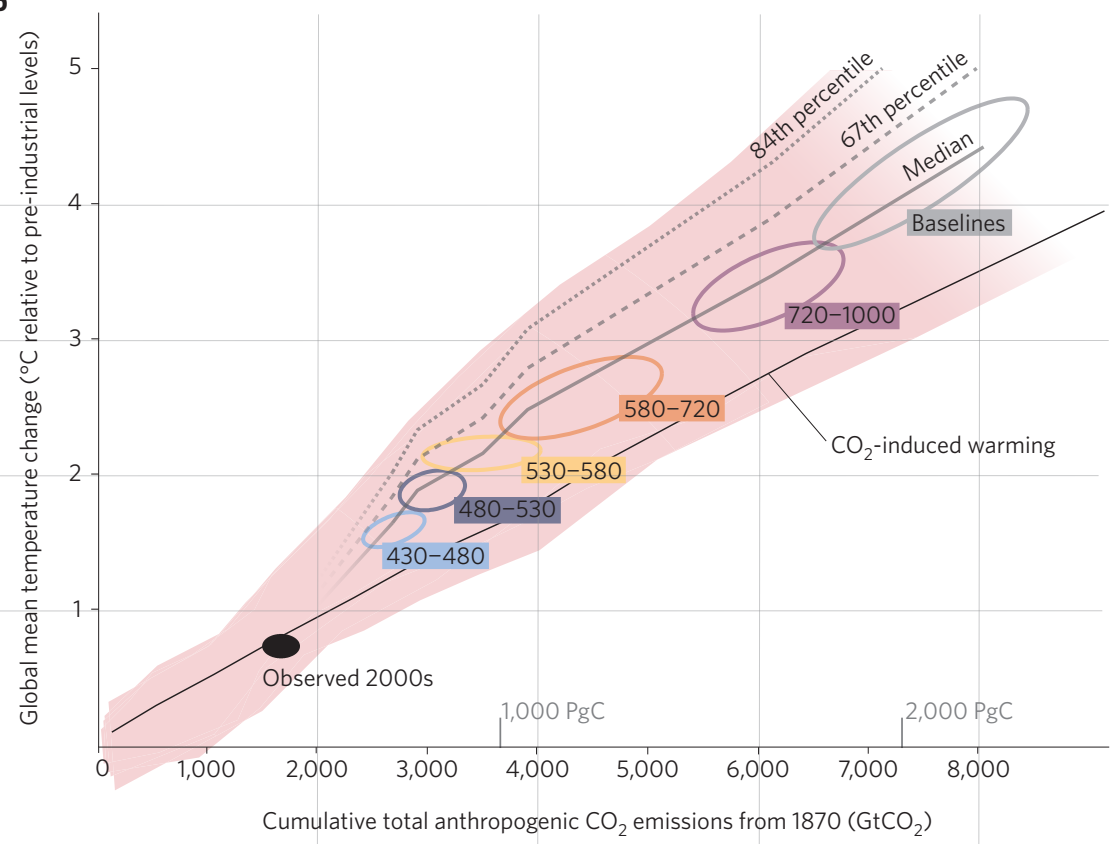

c

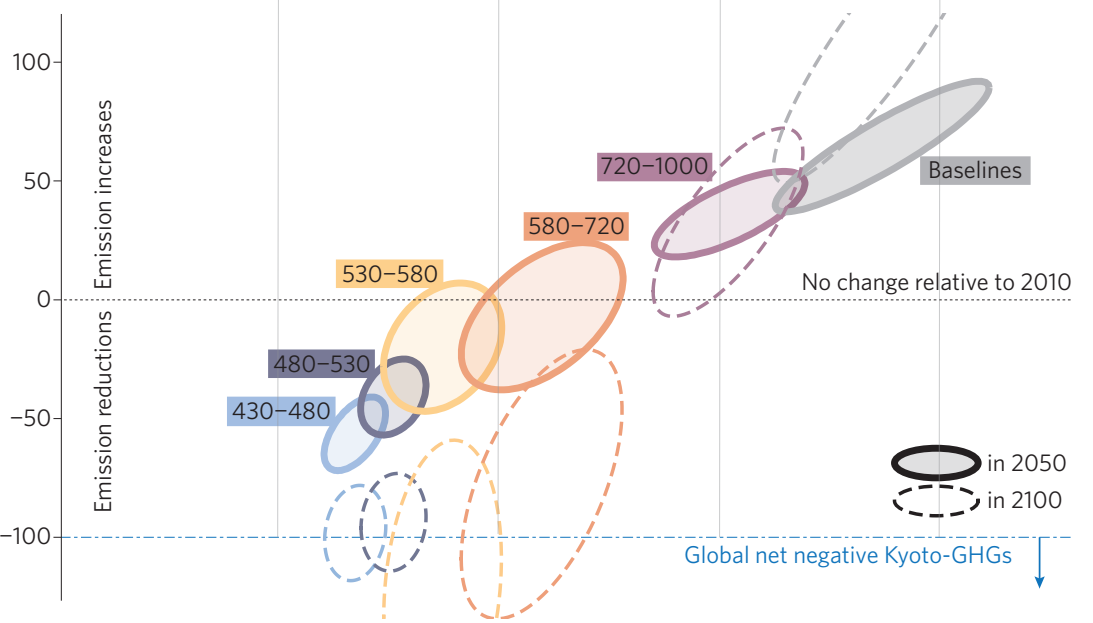

Figure 1 | The mapping of the relationship between risks from climate change, temperature change, cumulative $\mathrm{CO}_{2}$ emissions, and annual $\mathrm{GHG}$ emissions changes by $\mathbf{2 0 5 0}$ and 2100. a-c, Limiting the additional risks due to climate change across five reasons for concern (a), implies a limit for future cumulative emissions of $\mathrm{CO}_{2}(\mathbf{b})$, which constrains annual emissions over the next few decades and until the end of the twenty-first century (c). Figure adapted with permission from ref. 1 (c) 2015 IPCC.

\section{Linking risks and emissions}

Figure 1 links long-term climate change risks to their implications for annual emission levels under a broad range of scenarios. In Fig. 1a, the five 'reasons for concern' summarize how additional risks for societies and ecosystems change with increasing global mean temperature, compared with pre-industrial levels, as assessed in the Working Group II (WGII) contribution to the IPCC AR5 4 . Each reason for concern is anchored in different values and priorities: reflecting differences in the relative importance ascribed to the present versus the future; aggregate outcomes versus inequalities across individuals; most-likely versus possible extreme scenarios; and different categories of impacts. The reasons for concern are associated with: (1) unique and threatened systems, such as coralreef ecosystems and the societies dependent on them; (2) extreme weather events, such as heat waves and coastal flooding; (3) the uneven distribution of impacts, especially for poor communities and most-affected ecosystems; (4) global aggregate impacts, for example for Earth's biodiversity and the global economy; and (5) large-scale singular events, including, for example, ecosystem and ice-sheet tipping points. For each, the colour indicates the additional risk due to climate change when a temperature level is reached and then sustained or exceeded, reflecting the judgments of the AR5 authors based on the assessed literature.

Figure $1 \mathrm{~b}$ describes the relationship between cumulative $\mathrm{CO}_{2}$ emissions and temperature change, from the IPCC Working Group I (WGI) contribution to the AR5 $5^{5}$. Although warming also depends on concentrations of non- $\mathrm{CO}_{2}$ greenhouse gases (such as methane, nitrous oxide, hydrofluorocarbons, perfluorinated compounds and sulfur hexafluoride) as well as short-lived air pollutants such as soot and tropospheric ozone, the warming associated with $\mathrm{CO}_{2}$ emissions persists for many centuries, a result of the long-term persistence of some of the $\mathrm{CO}_{2}$ released to the atmosphere and the coupled dynamics of ocean-heat and $\mathrm{CO}_{2}$ uptake. The black solid line shows the consistent linear relationship between cumulative $\mathrm{CO}_{2}$ emissions since 1870 , and $\mathrm{CO}_{2}$-induced warming. Comparing this to the grey solid line, representing the median relationship between total global mean temperature change and cumulative $\mathrm{CO}_{2}$ emissions, shows that net non- $\mathrm{CO}_{2}$ warming is expected to increase, 
from near zero at present to over $0.5^{\circ} \mathrm{C}$ if cumulative $\mathrm{CO}_{2}$ emissions reach $4,000 \mathrm{GtCO}_{2}$ under the scenarios considered.

The shaded plume is based on comprehensive climate models assessed in WGI. It shows the uncertainty from the climate system response (multi-model $90 \%$ range), but because it is based on four emission scenarios only (the four representative concentration pathways or RCPs), it gives a limited sampling of the uncertainty arising from the balance between $\mathrm{CO}_{2}$ and non- $\mathrm{CO}_{2}$ emissions and the possible pathways of emissions through time.

The ellipses show the median climate response from a simple climate model, but provide a more exhaustive assessment of the uncertainty arising from roughly 1,200 different emission pathways, assessed in the Working Group III (WGIII) contribution to the IPCC AR5 ${ }^{6}$. The ellipses include baseline scenarios and mitigation scenarios, with differences in the mixture of gases and their timing of release. Baseline scenarios assume no new climate policy, whereas mitigation scenarios assume that additional policies are introduced beyond those in place today to reduce emissions.

Each ellipse corresponds to a specific category of scenarios defined by their climate forcing in 2100, expressed in terms of the $\mathrm{CO}_{2}$ equivalent concentrations in $\mathrm{ppm} \mathrm{CO}_{2}$-eq, and is labelled accordingly. The shape of the ellipses is derived from the distribution of data points available per category. In particular, the shapes and orientations of the ellipses correspond to those of the underlying point cloud. The ellipses are scaled based on the assessed ranges of cumulative $\mathrm{CO}_{2}$ emissions, temperature projection, or greenhouse gas (GHG) emissions reductions in a particular year, respectively, as assessed for each category by IPCC WGIII in the Table SPM.1 (in each case the 10-90th percentile is shown).

Any level of cumulative $\mathrm{CO}_{2}$ emissions can be linked to warming only with a certain confidence level. The grey lines show the maximum cumulative emissions associated with limiting warming to any temperature level with probabilities of 50\% (median response), $67 \%$ and $84 \%$ respectively, based on the comprehensive climate models under the four RCPs. To keep warming below $2{ }^{\circ} \mathrm{C}$, the probabilistic constraints imply an emission cap of $2,670 \mathrm{GtCO}_{2}$ (84\%), 2,800 $\mathrm{GtCO}_{2}(67 \%)$ and 3,140 $\mathrm{GtCO}_{2}$ (50\%). These probabilities of reaching the temperature target are useful benchmarks, but are very low compared with the probability of success usually applied in risk management, for instance in flood control or safety norms in industries.

Figure 1c links the cumulative $\mathrm{CO}_{2}$ emissions from 1870 to 2100 , to changes in annual GHG emissions in 2050 and 2100, relative to 2010 and using a 100-year global warming potential (GWP100) to aggregate across GHGs. This link is based on scenarios from integrated assessment models. Models mostly generate a cost-effective distribution of effort across time, sectors and countries, but an increasing number of scenarios also explore the implications of deviations from the least-cost pathways, including delays in additional mitigation (until 2030), different assumptions regarding technology costs and availability, or alternative distributions of mitigation effort. Each ellipse shows, for one scenario category, the range of changes in annual GHG emissions (vertical axis) in 2050 and 2100 consistent with a range of cumulative $\mathrm{CO}_{2}$ emissions until 2100 (horizontal axis). The $2670-2800 \mathrm{GtCO}_{2}$ budget range consistent with limiting warming to $2{ }^{\circ} \mathrm{C}$ with $67-84 \%$ probability is most closely aligned with the light-blue '430-480' scenario category, which corresponds to reductions in GHG emissions by $40-70 \%$ in 2050, relative to 2010. For limiting warming to any levels below about $2.5^{\circ} \mathrm{C}$, net $\mathrm{GHG}$ emissions in 2100 need to be negative or near zero (dashed-line ellipses).

The figure can also be read in reverse order from 1c to $1 \mathrm{a}$, to understand how policy choices about short-term emissions could result in different climate change risks over the long-term - if consistent pathways are followed and efforts are not relaxed over time. This use of the figure works well with the 'bottom-up approach' of the Paris Agreement, where countries commit to nationally determined contributions that are not determined based on an agreed global goal. It facilitates translation of emissions pathways (up to 2050) that are likely to result from a set of country commitments into the change in global temperature and resulting risks.

The figure indicates that scenarios without increased mitigation ambition lead to very high cumulative emissions in 2100 (around 6,500-8,000 $\mathrm{GtCO}_{2}$ from 1870, baseline ellipse in Fig. 1c), corresponding to warming between around $2.8^{\circ} \mathrm{C}$ and $5{ }^{\circ} \mathrm{C}$ (Fig. $1 \mathrm{~b}, 90 \%$ range). This corresponds to high to very-high risk levels across the reasons for concern. Policies implemented now to achieve a 50\% GHG emissions reduction by 2050 would be consistent with cumulative $\mathrm{CO}_{2}$ emissions of 2,500-3,200 $\mathrm{GtCO}_{2}$ from 1870 , corresponding to warming of about $0.8-2.7^{\circ} \mathrm{C}$. The resulting risks range from undetectable (for the lower temperature range and some reasons for concern) to high and very high (for the higher range and some reasons for concern), highlighting the large uncertainty in the full causal chain from policies to risks of impacts and the need for a riskbased understanding of the climate problem. These results should be used with caution, as there is no guarantee that the literature provides a statistically representative or exhaustive sample, and it is not possible to interpret these ranges in statistical terms.

Figure 1 supports and provides quantification for two important conclusions of the AR5. First, without additional policies, "warming by the end of the twenty-first century will lead to high-to-veryhigh risk of severe, widespread and irreversible impacts globally". Second, for any upper limit on warming, the world will eventually need to achieve zero net emissions of $\mathrm{CO}_{2}$ at the global scale, and $\mathrm{CO}_{2}$ and GHG emissions need to be close or below zero by the end of this century to maintain temperature below $2{ }^{\circ} \mathrm{C}$ compared to preindustrial levels. The figure can also inform decision-makers on the consequences of different choices regarding the long-term climate target and on the emissions reductions that are needed between now and 2050 and beyond to keep warming or climate change risks below certain levels. Specifically, it shows that reaching a "balance between anthropogenic emissions by sources and removals by sinks of greenhouse gases in the second half of this century" - one of the stated objectives of the Paris Agreement - does not guarantee stabilizing temperature below $2{ }^{\circ} \mathrm{C}$ : a number of scenarios achieve near-zero emissions by 2100 , yet still lead to warming of around $2.5^{\circ} \mathrm{C}$ (even with a median climate response). Further, capping only the global mean temperature is not sufficient to stabilize many other impacts, most notably the long-term impact of sea-level rise and ice-sheet melting?.

The figure - and the information on which it is based - was designed to map the climate change challenge in an integrated way, considering warming levels of up to $6{ }^{\circ} \mathrm{C}$. Because only few socioeconomic, policy, and climate scenarios were available for IPCC assessment that are consistent with a $1.5^{\circ} \mathrm{C}$ objective, the current mapping does not provide enough information on the difference in risks and needed action to compare $1.5^{\circ} \mathrm{C}$ and $2{ }^{\circ} \mathrm{C}$ targets. Recently, scenarios consistent with a $1.5^{\circ} \mathrm{C}$ limit have been published ${ }^{8}$. One important theme for future work is producing more scenarios from several research teams with temperature targets around the $1.5-2{ }^{\circ} \mathrm{C}$ range, and to explore the risks and opportunities that they entail. One output of this work could be a 'zoomed' version of the figure, specifically designed to inform the current debate on the long-term temperature goal.

\section{Uncertainty and decision-making}

In spanning different domains of the climate change issue, from the drivers of climate change to the Earth system response and climate policies, the mapping we present here necessarily aggregates diverse uncertainties. The overall uncertainty combines limitations in our knowledge of the climate system response - for instance, uncertainty in the relationship between radiative forcing and 
temperature change - with uncertainties intertwined with human choices - for instance, efforts to reduce emissions of $\mathrm{CO}_{2}$ versus non- $\mathrm{CO}_{2}$ gases. Aggregation and simplification, based on expert judgment, are inherent to assessment. At the same time, the different drivers of uncertainty have implications for decision-making that are important to explore.

Some of the uncertainty invokes considerations of precaution. For example, even if emissions remain within a $\mathrm{CO}_{2}$ budget that has a $67 \%$ chance of keeping warming below $2{ }^{\circ} \mathrm{C}$, there is a $33 \%$ probability that warming can be greater. Similarly, scenarios make assumptions on how technologies will evolve in the future. If the technological future turns out to be much less favourable than assumed in these scenarios, a goal decided in 2015 may prove infeasible by 2050 . It is not possible to quantify all these sources of uncertainty in a unique and objective way. In particular, the range of emission reductions in 2050 for different risk or temperature targets is based on the scenarios described in the literature, but cannot be associated with probabilities that could serve as an input for a probabilistic cost-benefit analysis or an (expected) cost-minimization approach.

These aspects highlight the deep uncertainty that surrounds the relationship between a long-term climate goal and the corresponding short-term policies ${ }^{9-11}$. From a risk management perspective, this uncertainty also implies the need to think about possible responses to worst-case scenarios and to monitor climate change and its impacts to detect as soon as possible departures from most-likely scenarios.

This is particularly crucial in the context of the $1.5^{\circ} \mathrm{C}$ and $2{ }^{\circ} \mathrm{C}$ limits that are part of the Paris Agreement's temperature goal. In this context, it is important to keep in mind that the short-term policies judged today to be consistent with these targets could actually lead to higher warming levels. This may happen, for instance, because a technology that is expected to play a key role after 2050 finally proves unavailable at the required scale. In particular, if negative emissions are not practical at the scale required, then some longterm climate goals may prove unattainable ${ }^{12,13}$. The uncertainty is especially linked to the unknown capability of bioenergy with carbon capture and sequestration and other $\mathrm{CO}_{2}$-removal technologies to deliver large negative emissions ${ }^{14,15}$. A similar situation may arise if the warming in response to greenhouse gases is at the high end of the uncertainty range, making the scenarios that are currently considered consistent with $1.5^{\circ} \mathrm{C}$ or $2{ }^{\circ} \mathrm{C}$ reach higher warming. Comparing a $1.5^{\circ} \mathrm{C}$ and a $2{ }^{\circ} \mathrm{C}$ target is therefore not about comparing impacts in a $1.5^{\circ} \mathrm{C}$ and a $2{ }^{\circ} \mathrm{C}$ world: it is about comparing risks, including the risks of finally ending up at a much higher warming ${ }^{16}$. And indeed, to compare the costs and benefits of selecting the longterm target, one has to take into account that one of the main benefits of adopting a $1.5^{\circ} \mathrm{C}$ long term target over a $2{ }^{\circ} \mathrm{C}$ target is that it reduces the likelihood of a much higher warming, and limits the climate risks posed by key technologies not delivering in the future.

In contrast, some aspects of uncertainty can be viewed as opportunities to learn and adjust responses ${ }^{9,11,17}$. Learning over time opens opportunities to adjust climate policies flexibly based on new information and knowledge. The mapping exercise suggests a large uncertainty in the link between a given level of emissions in 2050 and the expected temperature change. This uncertainty is due in part to the existence of multiple pathways to achieve any climate goal: it is possible to compensate modest short-term mitigation efforts if larger efforts are made later in the century, and, conversely, the climate benefits of early mitigation efforts can be undone if mitigation efforts are relaxed after 2050 .

At the same time, the range of targets that can be achieved at a given cost - with a given level of mitigation risk and with a given probability of success - will be increasingly narrowed over time if emissions are only moderately reduced in the short-term ${ }^{18-21}$. The window of options is rapidly closing ${ }^{22-24}$. Although there are multiple possible pathways to achieve a temperature objective, rapidly growing risks and economic, social and political costs - which are not represented in the figure - create urgency ${ }^{12}$.

Aggregating these uncertainties may give decision-makers the impression that we know less than we actually do and insufficiently communicate the degrees of freedom that exist in the design of global climate policies. A priority for future research is to go beyond the assessment of uncertainty and investigate the source of these uncertainties and how they affect decision-making, and to develop new and better tools to communicate this information in a way that is actionable.

\section{Action timing and non- $\mathrm{CO}_{2}$ gases}

The central link in Fig. 1 is a budget expressed in cumulative $\mathrm{CO}_{2}$ emissions ${ }^{5}$. The cumulative emissions approach emphasizes the important conclusion that, for any upper limit on warming, that is, the world will eventually need to achieve zero net emissions at the global scale. But what are the limits of such an approach? A multitude of emission pathways are able to reach a given target. These pathways differ in terms of distribution of efforts over time and of allocation of efforts between $\mathrm{CO}_{2}$ and non- $\mathrm{CO}_{2}$ gases and aerosols.

Climate stabilization implies a limited cumulative $\mathrm{CO}_{2}$ budget. Figure $1 \mathrm{~b}$ includes an idealized scenario noted $\mathrm{CO}_{2}$-induced warming, that is, the median warming in the models with $\mathrm{CO}_{2}$ as the only GHG. This scenario provides a benchmark for the relative contribution of $\mathrm{CO}_{2}$ and non- $\mathrm{CO}_{2}$ gases. All scenarios envisage non- $\mathrm{CO}_{2}-$ induced warming to increase in the future, but in the large majority of scenarios, there is a strong correlation between the emissions of $\mathrm{CO}_{2}$ and non- $\mathrm{CO}_{2}$ gases. This correlation is in part due to the fact that cost-effective scenarios assume a uniform level of effort across all GHGs (for instance through an economy-wide carbon price), but it also arises from the fact that $\mathrm{CO}_{2}$ and non- $\mathrm{CO}_{2}$ gases are partly released from common sources and therefore linked ${ }^{25,26}$. The correlation between $\mathrm{CO}_{2}$ and non- $\mathrm{CO}_{2}$ gases will thus not disappear in scenarios with fragmented (sector-scale) policies, even though it will be weaker. A carbon budget is a simplification, but it is a useful simplification for the communication of the climate change challenge and policy options.

Still, different pathways of emissions with the same cumulative $\mathrm{CO}_{2}$ budgets may lead to different rates of climate change, even if the long-term warming is unchanged. Over the next few decades, substantial reductions in both $\mathrm{CO}_{2}$ emissions and emissions of non- $\mathrm{CO}_{2}$ short-lived climate pollutants such as methane, soot and tropospheric ozone precursors can slow the expected rate of climate change even though the impact of short-term emissions of shortlived pollutants on long-term temperature is limited ${ }^{25}$. Lower rates of climate change, in turn, can reduce risks for ecosystems and societies, reduce the risk of crossing tipping points ${ }^{27,28}$, and increase the potential for adaptation 4 . Further, the assumption that net negative emissions will be achievable later in the century leads to mitigation scenarios that temporarily exceed the compatible $\mathrm{CO}_{2}$ budget. This leads to a temperature overshoot, which in turn has implications for societies and ecosystems. The rate of warming is included in the assessment of some of the reasons for concern, but the assessment here does not include a limit on acceptable rate of change.

More generally, accounting for peak warming (instead of the stabilization level or end-of-century warming) and additional metrics of climate change, such as the rate of change, local impacts or ocean acidification impacts, could change the assessment of various longterm climate goals and short-term mitigation policies ${ }^{29}$. Although Fig. 1 provides a useful summary of climate risks, it cannot encompass the full complexity of the climate problem, and decision-makers have to go beyond stabilized global temperature as they consider the consequences of various emission pathways. These additional metrics and local and dynamic aspects also create a wedge between the Article 2 objective of the UNFCCC - avoiding dangerous climate 
change - and the current debate on a long-term goal expressed as a long-term limit on warming. This is particularly important for the assessment of climate change mitigation options, such as geoengineering, that may maintain the global temperature below a certain level, but with important and unintended side-effects that emerge only under alternative metrics. A world with a $1.5^{\circ} \mathrm{C}$ warming reached through reduced GHG emissions implies very different risks than a world with the same level of warming reached through geoengineering options such as solar radiation management.

Finally, decision-makers have to account for the consequences of short-term decisions, which create long-term commitments. Specifically, emission reductions at the low end of the 2050 range consistent with the $2{ }^{\circ} \mathrm{C}$ target (for example, around $40 \%$ ) create a commitment to climate policies with more rapid reductions and larger negative emissions - beyond 2050. Defining the level of short-term action that is sufficient to achieve a given target depends on what is deemed realistic over the long-term ${ }^{18}$. Defining what is possible or realistic is not straightforward, as it depends less on technical or economic feasibility than on political and social acceptability $^{22}$. As a result, defining a short-term emission gap (or a climate action gap) for any long-term objective remains challenging and partly subjective.

\section{Climate change and climate policy risks}

The mitigation scenarios underpinning Fig. 1 all fundamentally depart from continued high emissions. They involve the global transformation of energy and land-use systems, whether they hold warming below $1.5{ }^{\circ} \mathrm{C}, 2{ }^{\circ} \mathrm{C}$ or $3{ }^{\circ} \mathrm{C}$ by 2100 . There are costs and risks associated with the required mitigation policies and measures. In addition, mitigation policies can generate immediate cobenefits, for example, better air quality and health benefits or more comfortable buildings that are also less costly to heat or air condi$\operatorname{tion}^{30}$. Although a $1.5^{\circ} \mathrm{C}$ target may look unambiguously safer than a $2{ }^{\circ} \mathrm{C}$ target when focusing on climate change risks, the picture may become more complex if mitigation risks are accounted. Ideally, a mapping exercise should enable comparison of the risks of climate change impacts (in Fig. 1a) with the costs and co-benefits associated with emissions changes (depicted in Fig. 1c).

This limitation has consequences on how the figure can and should be used. Although the figure shows many different pathways compatible with a given temperature target, the 'feasibility' of these pathways also depends on the economic cost and social and political acceptability of the corresponding policies and measures ${ }^{22}$. The flexibility - and option to delay mitigation action - that the figure may suggest does not fully include these economic, social and political constraints. Introducing these factors - arguably a difficult challenge - would lead to removal of some of the pathways shown in the figure and reduce the flexibility in the choice among pathways.

What are options to include these additional factors? Efforts that attempt to define an 'optimal' long-term climate goal have often focused on estimates of macroeconomic costs, comparing costs of climate change impacts and mitigation costs. Aggregate costs of climate change impacts, however, are only one component of one of the five reasons for concern and cannot adequately encompass all dimensions of impacts. Similarly, mitigation costs, benefits and risks cannot be adequately summarized in a single number in an objective way, because, for example, consequences for regional versus local well-being or time preferences vary strongly. Risks of nuclear accidents, food shortages from increased land competition due to bioenergy production, or the loss of an important industry are assessed in the WGIII contribution of the IPCC AR5, but they cannot be summarized in a single number ${ }^{6,31}$. One option for future research is to more fully evaluate and quantify the risks from mitigation, potentially in a summary framework such as reasons for concern. This is particularly important for aggressive mitigation pathways, with rapid decrease in emissions or large negative emissions, as these pathways may imply trade-offs with other policy objectives such as universal access to energy or the preservation of biodiversity. As flagged by others ${ }^{14}$, exploring the risks linked to a massive use of bioenergy paired with carbon capture and sequestration, to achieve large negative emissions, should be a priority for future research.

The resulting risk-risk comparisons would still be difficult and dependent on values and preferences, especially because the reasons for concern linked to climate change risks and those linked to mitigation risks will be very different and therefore not directly comparable. Critical differences will include: (1) limits to our ability to manage risks (that is, limits to adaptation to climate change impacts but also to side effects of mitigation); (2) opportunities for co-benefits linking adaptation and mitigation with sustainable development; and (3) the irreversibility created by different risks.

For example, the figure does not show that mitigation efforts can be adjusted over time as we learn their costs and consequences. In contrast, climate change and its impacts involve irreversibility over centuries and beyond, placing limits on learning and adjustment ${ }^{4}$. For decision-makers, this asymmetry in irreversibility supports a precautionary approach, with significant short-term mitigation efforts that can be relaxed over time if more information rules out the most pessimistic climate change and technology scenarios. Such adjustment in mitigation policies could be informed by regular assessments, including through revisions of Fig. 1, accounting for better information on climate system dynamics, impacts on ecosystems and societies, and mitigation technologies, costs and more detailed and regionalized risk categories. International climate agreements therefore have to be designed as iterative risk management tools. The challenge is to balance the need for predictability and credibility of country commitments with enough flexibility to allow for regular revisions in light of new information and feedback from existing climate policies.

Finally, Fig. 1 encompasses risks and climate policies intertwined with development pathways, but it does not make explicit linkages with development. Depending on what development pathway is followed, climate change impacts and climate policies can result in very different risks. Risks will be lower in a future world in which: local and global governance improves; natural resources are used efficiently and managed sustainably; technological change is swift and directed toward sustainable options; and development is rapid and inclusive ${ }^{32}$.

Ill-designed mitigation policies could impact development pathways in a way that reduces the adaptive capacity of ecosystems (because habitats are threatened by bioenergy), or of economies and societies (by slowing poverty alleviation or access to universal energy), increasing the overall impacts of climate change. A new set of socioeconomic scenario pathways - currently under development - will allow for a better consideration of these issues and be a pillar in the literature assessed as part of the 6th assessment cycle of the IPCC ${ }^{33,34}$

But over the short term, decision-makers will have the difficult task of bringing together the climate agenda with their development goals and strategies, at the domestic and international levels. In September 2015, the United Nations General Assembly in New York City adopted the Sustainable Development Goals, which will influence development policies over the coming decades. A few months later, the twenty-first Conference of the Parties of the UNFCCC in Paris set up the future international architecture to stabilize climate change. Future research - and future IPCC assessments - should help decision-makers harmonize these two agendas and make the long-term climate goal an integral part of the development agenda.

Received 23 February 2016; accepted 17 May 2016; published online 23 June 2016 


\section{References}

1. IPCC Climate Change 2014: Synthesis Report (eds Pachauri, R. K. \& Meyer, L. A.) (Cambridge Univ. Press, 2014).

2. Knutti, R., Rogelj, J., Sedláček, J. \& Fischer, E. M. A scientific critique of the two-degree climate change target. Nature Geosci. 9, 13-18 (2016).

3. Edenhofer, O. \& Minx, J. Mapmakers and navigators, facts and values. Science 345, 37-38 (2014).

4. IPCC Climate Change 2014: Impacts, Adaptation, and Vulnerability. Part A Global and Sectoral Aspects (eds Field, C. B. et al.) (Cambridge Univ. Press, 2014).

5. IPCC Climate Change 2013: The Physical Science Basis (eds Stocker, T. F. et al.) (Cambridge Univ. Press, 2013).

6. IPCC Climate Change 2014: Mitigation of Climate Change (eds Edenhofer, O. et al.) (Cambridge Univ. Press, 2014).

7. Clark, P. U. et al. Consequences of twenty-first-century policy for multi-millennial climate and sea-level change. Nature Clim. Change 6, 360-369 (2016)

8. Rogelj, J. et al. Energy system transformations for limiting end-of-century warming to below $1.5^{\circ} \mathrm{C}$. Nature Clim. Change 5, 519-527 (2015)

9. Ha-Duong, M., Grubb, M. J. \& Hourcade, J.-C. Influence of socioeconomic inertia and uncertainty on optimal $\mathrm{CO}_{2}$-emission abatement. Nature 390, 270-273 (1997).

10. Lempert, R. J. \& Schlesinger, M. E. Robust strategies for abating climate change. Climatic Change 45, 387-401 (2000).

11. Yohe, G., Andronova, N. \& Schlesinger, M. To hedge or not against an uncertain climate future? Science 306, 416-417 (2004).

12. Clarke, L. et al. in Climate Change 2014: Mitigation of Climate Change (eds Edenhofer, O. et al.) Ch. 6 (IPCC, Cambridge Univ. Press, 2014).

13. van Vuuren, D. P. \& Riahi, K. The relationship between short-term emissions and long-term concentration targets. Climatic Change 104, 793-801 (2010).

14. Smith, P. et al. Biophysical and economic limits to negative $\mathrm{CO}_{2}$ emissions. Nature Clim. Change 6, 42-50 (2016).

15. Williamson, P. Emissions reduction: scrutinize $\mathrm{CO}_{2}$ removal methods. Nature 530, 153-155 (2016)

16. Fawcett, A. A. et al. Can Paris pledges avert severe climate change? Science 350, 1168-1169 (2015)

17. Otto, F. E. L., Frame, D. J., Otto, A. \& Allen, M. R. Embracing uncertainty in climate change policy. Nature Clim. Change 5, 917-920 (2015)

18. Kriegler, E. et al. Introduction to the AMPERE model intercomparison studies on the economics of climate stabilization. Technol. Forecast. Soc. 90, 1-7 (2015).

19. Luderer, G. et al. Economic mitigation challenges: how further delay closes the door for achieving climate targets. Environ. Res. Lett. 8, 34033 (2013).

20. Rogelj, J., McCollum, D. L., O’Neill, B. C. \& Riahi, K. 2020 emissions levels required to limit warming to below $2{ }^{\circ} \mathrm{C}$. Nature Clim. Change 3, 405-412 (2013)

21. von Stechow, C., Minx, J. C. \& Riahi, K. $2{ }^{\circ} \mathrm{C}$ and the sustainable development goals: united they stand, divided they fall? Environ. Res. Lett. 11, 034022 (2015).
22. Guivarch, C. \& Hallegatte, S. 2C or not 2C? Glob. Environ. Change 23, 179-192 (2013)

23. Pfister, P. L. \& Stocker, T. F. Earth system commitments due to delayed mitigation. Environ. Res. Lett. 11, 14010 (2016).

24. Stocker, T. F. The closing door of climate targets. Science 339, 280-282 (2013)

25. Rogelj, J. et al. Disentangling the effects of $\mathrm{CO}_{2}$ and short-lived climate forcer mitigation. Proc. Natl Acad. Sci. USA 111, 16325-16330 (2014).

26. van Vuuren, D. P., Weyant, J. \& de la Chesnaye, F. Multi-gas scenarios to stabilize radiative forcing. Energ. Econ. 28, 102-120 (2006).

27. Lenton, T. M. Environmental tipping points. Annu. Rev. Environ. Resour. 38, 1-29 (2013).

28. Stocker, T. F. \& Schmittner, A. Influence of $\mathrm{CO}_{2}$ emission rates on the stability of the thermohaline circulation. Nature 388, 862-865 (1997).

29. Steinacher, M., Joos, F. \& Stocker, T. F. Allowable carbon emissions lowered by multiple climate targets. Nature 499, 197-201 (2013).

30. McCollum, D. L. et al. Climate policies can help resolve energy security and air pollution challenges. Climatic Change 119, 479-494 (2013).

31. von Stechow, C. et al. Integrating global climate change mitigation goals with other sustainability objectives: a synthesis. Annu. Rev. Environ. Resour. 40, 363-394 (2015)

32. Hallegatte, S. et al. Shock Waves: Managing the Impacts of Climate Change on Poverty (World Bank, 2016).

33. O'Neill, B. C. et al. A new scenario framework for climate change research: the concept of shared socioeconomic pathways. Climatic Change 122, 387-400 (2013).

34. Vuuren, D. P. van. et al. A new scenario framework for climate change research: scenario matrix architecture. Climatic Change 122, 373-386 (2013).

\section{Acknowledgements}

This paper benefited from many discussions with all the authors of the AR5 Synthesis Report of the IPCC, many authors from the three Working Groups, and members from the government delegations during the approval plenary in Copenhagen, 2014. Marianne Fay, Jan Fuglestvedt and Brian O'Neill provided useful comment on previous versions of the manuscript.

\section{Author contributions}

All authors contributed to the assessment of the literature, the design of the figure and concepts and the writing of the paper.

\section{Additional information}

Reprints and permissions information is available online at www.nature.com/reprints. Correspondence and requests for materials should be addressed to S.H.

\section{Competing financial interests}

The authors declare no competing financial interests. 